\title{
First Responders to Superstorm Sandy; An Information Technology Assessment
}

\author{
Thomas Virgona, PhD. \\ Adelphi University Assistant Professor / Director of the Master of Science Program in Healthcare Informatics \\ Alumnae Hall / College of Nursing and Public Health - Room 232
}

\begin{abstract}
Traditionally, first responders, (e.g., Emergency Medical Technicians) have under-invested and lagged other provider groups in the utilization of state-of-the-art technologies. This can be partially attributed to a lack of fiscal support or an inability to identify needs that may warrant fiscal support. Consequently, the goal of this research is to determine the information technology needs of first responders. The findings will influence matching funding with current needs in this area. This pilot study, conducted in the aftermath of Superstorm Sandy, describes which Information Technology worked and identifies areas for future information technology improvements for first responders.
\end{abstract}

\section{Introduction}

The future direction of the Health Information Technology is a contemporary topic of significant importance to the country. Today there are major changes as a result of legislation in the areas of health care and how health care will be delivered and paid for across the population. Traditionally, first responders, (e.g., Emergency Medical Technicians) have under-invested and lagged other provider groups in the utilization of state-of-the-art technologies. This can be partially attributed to a lack of fiscal support or an inability as a group to identify needs that may warrant fiscal support. Consequently, the goal of this research is to determine the information technology needs of first responders. This may influence an ability to match funding with current needs in this area. The proposed study is a pilot where the results will lead to proposing a similar study on a much larger population.

\section{Literature Review}

Medical care is dependent on quality information. In many circumstances, this information is provided to medical providers in a non-traditional setting, such as an emergency or accident site. Lessons learned from prior research in this area directs the focus on usable data and versatile technologies for first responders as well as methods for preparedness. (Dawes, Cresswell, \& Cahan, Apr 2004)

Many experts have called for better information in emergency situations.

Philip Powers, Director of Health Informatics, Health Policy Institute of Ohio, Columbus "Having accurate identification and medical information to give to emergency physicians and staff in advance can mean the difference between good treatment and errors, and life and death." (Anonymous, 2013)

"The health care system will be turned upside-down in a minute if a disaster strikes. Will information systems even be in place? People will want help, but medical histories will be important. Education also is essential for consumers to be prepared." Anne Llewellyn, Managing Editor, Dorland Healthcare, Philadelphia (Anonymous, 2013)

"The need for the government to step up the funding of services in the area of health information technology will assure that we are prepared for the many challenges to come." Christopher Greene, Lawrenceville, Ga. (Anonymous, 2013)

Secretary Tom Ridge opened the 2004 Technologies for Public Safety in Critical Incident Response Conference and Exposition in New Orleans (won't be last week by time published) last week by calling for improved technology to help the nation's first responders convey information more efficiently in times of crisis. (Chris, 2013)

\section{Challenges}

There are challenges for first responders obtaining critical Information. Jere believes that the lack of a unified Health Information Exchange (HIE) is an issue. He explains that most of the HIE systems reside in state and regional clusters. This arrangement he writes presents a significant logistical drawbacks in that much of the gathering and use of this information occurs outside of the hospital (most of the emergency use of this data will occur in places where wireless/mobile service and connectivity are unreliable). Further state regulations regarding HIEs and HIT (health information technology) are still being defined (Jere, 2013). 
Another challenge presented is that first responders to a major incident may include many different agencies. These may include law enforcement officers, fire departments, paramedics, HAZMAT response teams, and possibly even federal personnel such as FBI and FEMA. Often times multiple jurisdictions respond to the incident which causes interoperability issues with respect to communication and dissemination of time critical information. Accurate information from all responding sources needs to be rapidly collected and made available to the current on site responders as well as the follow-on responders who may just be arriving on scene. First Responders often arrive in mobile vehicles that are equipped with communications equipment and may make reports back to their home based command centers. Many times, the details of those reports are not typically available to other first responders who are not a part of that agencies infrastructure. Furthermore, the collection of information often occurs outside of the first responders' vehicle and the details of the scene are normally either radioed from the field or written down and then disseminated after significant delay (Messner, Hludik, Vidacic, \& Melnyk, 2005). The transmission of information from point to point can lead to lost or misinformation.

\section{Current Information System Tools and Systems}

A number of groups have developed systems designed to improve the management of medical information in mass casualty events. In general, such systems have two components: victim tracking (often called mass casualty tracking) and field care management. (L A Lenert, 2011). Field care systems are systems designed for use in mobile environments for initial stabilization of victims with electronic health record (EHR)like features. Different systems have been developed for different use cases with different technologies. For example, Battlefield Medical Information System Tactical-Joint (BMIST-J) was developed for use by Army medics in the field and avoids radio-frequency identification (RFID) technologies to prevent enemies from targeting wounded soldiers by signal tracking. Other systems, such as the Raytheon system focused on using the capabilities of existing cellular systems and devices for mass casualty tracking. Still other groups have explored the possibilities of using Motes, a type of low-power computer designed for networked sensor applications, for disaster response applications. Investigators also have studied the use of WiFi (802.11) systems for monitoring of patients' vital signs and other telemetry as part of comprehensive systems for field care. (L A Lenert, 2011) Emergency management can be described as an iterative planning activity that call for a high level of coordination between multiple stakeholders: first responders, citizens, volunteers, subject matter experts, scientists, technicians and managers with different yet important responsibilities. In a typical crisis event existing systems and communications infrastructures may not provide necessary information in a timely fashion due to damage, incompatible media, geographically limited coverage, fragmented technology or social and policy issues. The coordination of multiple response units/resources is hindered by incompatible communication technologies and social/policy incongruences.

One information technology that addresses these issues is the Intelligent Deployable Augmented Wireless Gateway (or iDAWG). This software technology creates direct communication networks between remote coordinators, local response teams, volunteers and others on location by using or replacing existing communication or network infrastructures. Remotely sensed information and communications can be shared in real time via iDAWG-enabled devices that can be configured on the fly using edgeware (a new class of software developed for the wireless grid) applications. Existing web, cellular and radio communications network devices are bridged to build dynamically scalable heterogeneous wireless grids. Technical, social, governance and policy issues are addressed to facilitate this paradigm change in emergency response. (Marsden, 2012)

Another technology that was designed for first responders is the AlphaACT system. A number of psychological theories support the core principles of the AlphaACT system. This case-based system is designed to emulate how successful decision makers think in crisis situations, and trains users to follow a decision process inspired by CBR theory and the RPD model. (An T. Oskarsson, 2010) The essential components of the system are as follows:

(a) A user interface that walks the decision maker through a multi-step decision process inspired by the recognition-primed decision model and case-based reasoning theory;

(b) A pattern recognition engine that prompts the user for diagnostic information and retrieves similar cases; and (c) A community-wide shared knowledge base of cases that grows as the system is used.

AlphaACT's objective is to train and enable responders in crisis situations to think like experienced decision makers, and to quickly build their store of available experiences. The first AlphaACT application under development will support key decisions made by first responders managing a hazardous materials emergency.

An ambitious technology currently being tested is the WIISARD system. WIISARD shows that wireless EMR systems that care of the victims of disasters would be complex to develop but potentially feasible to build and deploy, and likely to improve the quality of information available for the delivery of care during disasters. (L A Lenert, 2011) 
Smart911, which is funded in communities with 9-1-1 surcharge funding, provides citizens with the ability to enter information that they want to make available to 9-1-1 call takers through a secure website at www.Smart911.com. Information can include children's photos, medical conditions, disabilities, home addresses of cellphone callers, or other rescue-related information. Smart911 then delivers this information automatically to the call taker's work station with any 9-1-1 call at a participating PSAP. The service, which is free to citizens, enhances response and supports improved incident outcomes, by providing responders with critical additional information. It also supports citizen demand for the ability to easily provide and manage special needs data. Smart911 is a national system--once the data is entered by an individual, it can be viewed by any PSAP that has deployed Smart911 across the United States. (Anonymous, Smart911 Improves Safety for Nearly 4 Million Citizens throughout United States, 2011)

In addition to medical information, first responders (e.g. EMT's) also need logistical information. PrePlanView, a software preplan system that provides information to first responders during an incident, for the Saint Clair Shores Fire Department (SCSFD) in Michigan. The use of the software allowed first responders at SCSFD to create building plans, access information on buildings, view building and site plans in threedimension (3D), and display information on hydrant, hazardous materials, building and contacts. (Kovalcik, 2010)

The spreading of inaccurate or misleading information can have disastrous consequences in the chaotic and hazardous environments which are prevalent in large-scale disasters. Therefore it is imperative that the responders possess the ability to assess and evaluate the trustworthiness as well as the information propagated by fellow responders in order to facilitate collaboration. (Dionysios Kostoulas, 2008)

\section{Problem Statement}

This research proposes to determine informational technology needs of First Responders/EMT workers and to describe perceived barriers with the use of technology, and ways technology can assist EMT first responders.

\section{Research Questions}

- What are the Information Technologies that proved beneficial during response?

- What are the Information Technologies that were not available but would have been beneficial during response? What do you feel are the obstacles in obtaining the desired Information Technologies?

\section{Methods}

For this study, a survey developed by the researcher was distributed to first responders in the Village of East Rockaway, New York. The researcher attended a regularly scheduled department East Rockaway Fire Department Wednesday meeting. The researcher described the study, participation was voluntary and there was no incentive or measure of gratitude for participation. The definition of first responders in this study includes; Fireman, Emergency Medical Technicians, and Rescue Workers. The survey instrument had two major questions and demographic data was distributed to volunteers. Fifteen minutes was allowed for the completion of the survey.

\section{Data Analysis}

Ideally, every first responder would be included in this study. We do not have the time or resources to study the entire population of first responders, so we resolve study a subset of the population. The research was designed to include a representative sampling of first responders. As the impact of Superstorm Sandy lasted for several months, this required many first responders for outside agencies (e.g., FEMA, New York National Guard, The Red Cross, etc.) to spend extended time in local firehouses. The result was the participants in this study was broader than originally anticipated.

The data from the surveys was analyzed as a whole. The open-ended questionnaire yielded both qualitative and quantitative data. A brief Demographic Data Form was used to collect such information as age, experience and current job title. Demographic data will be used to describe the sample. The second set of data was qualitative, the responses to two questions attached. The responses were coded and analyzed for categories related to available and not-available technology.

The timing and geographic location of this study should also be noted. The methodology for this research was designed during September 2012 and Institutional Review Board Approval was granted in October 2012, the surveys were not conducted until December 2012, just weeks after Superstorm Sandy the town of East Rockaway. As a result, much of the respondents' focus was on the events of the three days following the storm. Thus how they responded to this emergency vs. day to day emergencies and the technology needed must be taken into consideration when reviewing the findings.

Three questions then arose; 
- $\quad$ Should Satellite phone be used as a standard practice?

- Should Satellite phone be used as a backup communication system?

- What is the cost impact of implementing satellite phones?

\section{Demographic data}

Respondents; Male and Female

\begin{tabular}{|l|l|l|l|}
\hline & Men & Woman & Total \\
\hline Respondents & 24 & 3 & 27 \\
\hline Average Age & 38 & 26 & 37 \\
\hline
\end{tabular}

Respondents; Job Title

\begin{tabular}{|l|l|l|l|}
\hline & Men & Woman & Total \\
\hline Fireman & 24 & 2 & 26 \\
\hline Emergency Medical Technician & 11 & 3 & 14 \\
\hline Rescue & 9 & 3 & 12 \\
\hline
\end{tabular}

*Note; an individual may have multiples roles.

\section{Technology Issues}

During Sandy, and the days that immediately followed, one technology proved reliant, the pager system. The pagers are a one way communication system from a control unit to department members. All members of the fire, rescue and EMT units were notified of incidents immediately and were able to hear critical updates. Additionally, the communications between 911 and the East Rockaway village dispatcher had no issues.

Several Information Technologies proved to be problematic during the storm. The Headquarters for the Fire Department had to be evacuated due to the storm surge and the flooding the resulted. Several printers and other communications devices were left behind and/or damaged. The two-way radio devices at that point were not fully functional, although the exact reason was not identified. One Fire Truck company went out on a call and could not be contacted, forcing another Fire company to start a search for the "lost" team. It should also be noted that department policy states that units are not to respond to emergency during a severe storm (e.g., winds greater than 55 miles per hour). That policy was largely ignored.

GPS systems were used extensively during the storm. While the drivers (also known as chauffeurs) were intimately familiar with their own districts, many calls required that the department leave their districts and assist (or provide mutual aid) to other localities (e.g., Long Beach, New York). It should be noted that not all of the Fire Departments or Rescue Units came with GPS systems.

Rescue workers, including EMT workers and Fireman, are totally dependent on information provided to them by 911 callers and dispatchers. During an emergency, local policy requires a confirmation before a unit responds. However, the process for confirmation remains unclear. Two incidents were cited and correct information processing, but bad information. The fire department was asked to respond to a house fire ("fully engulfed"). Once the fire department arrived, it was an elderly couple that needed to be evacuated due to the rising flood waters. Another call to the rescue unit was to respond to a woman that pregnant. The National Guard responded, and their truck sank on the front lawn. The woman was not in labor and needed to be evacuated. Both of these incidents occurred in an area where there was a mandatory evacuation order issued.

In response to the question; "What Information Technologies would have been beneficial during the Superstorm crisis, thirteen respondents cited the same item - an online 'map' of the area. The map would show the area which each group is responsible on a large screen showing the following data;

- Weather information

- $\quad$ Locations of active fire/EMS calls for the area (depicted with icons)

- Current locations of all vehicles

- $\quad$ Critical information status updates (e.g., no access to diesel fuel as town garage is flooded)

Other beneficial technologies cited during this study was the desire for more visual communication devices. The quality of information transmitted on pagers and radio's tends to be low and difficult to understand during an emergency. A visual device would assist in understanding messages that are communicated.

The single biggest barrier to obtaining the desired technologies is funding, according to the respondents. Local municipalities are not in a position to purchase state of the art equipment in the current economic climate. The second barrier to obtaining desired technologies is a lack of knowledge of the product that are available. While the respondents detailed what they feel would help in emergency situations, none knew of firms that manufactured the products. Additionally, no respondents were familiar with any of the technologies listed in the literature review for this research (PrePlanView, Smart911, AlphaACT) 


\section{Conclusions}

While no system will be completely functional in all of these settings, the objective of research in disaster informatics is to identify the principles that will maximize the utility of systems across settings. While no system will be completely functional in all of these settings, the objective of research in disaster informatics is to identify the principles that will maximize the utility of systems across settings.

One example of a notification technology is a paging or alerting messaging to a guardian or parent of a child who is struck ill while at school or on a trip (Jere, 2013). Several respondents also suggested the use of Satellite phones, noting the unreliability of land and cellular phones during emergencies.

Also discussed was special GPS software for fire department. The added functionality would include locations of fire hydrants. Many fire hydrants could not be located during superstorm Sandy due to no street lights or submerged due to the tidal surge. All digital equipment should be on the passenger side of the units, as the driver does not need any additional distractions.

The creation of a common central database with a simple easy to use interface that is dynamically updated in real time would allow prompt and efficient information distribution between different jurisdictions. Such a system is paramount to the success of any response to a major incident. (Messner, Hludik, Vidacic, \& Melnyk, 2005)

Since first responders are not usually on the same communications channels, and the fact that there is normally a considerable amount of confusion during the first few hours on scene, it would be beneficial if there were a centralized location for the repository of time critical information which could be accessed by all the first responders in a common fashion without having to redesign or add significantly to each first responders hardware/software systems. Each first responder would then be able to provide information regarding their particular situation and such information could be accessed by all responding personnel. This will require the transmission of information provided by the first responder to a common central database system. In order to fully investigate the use of technology, it is advantageous to build a test bed in order to evaluate the proper hardware/software necessary, and explore the envisioned scenarios of operation before deployment of an actual system.

Future research should include focus on the decision makers that purchase information systems for emergency workers and determine the analysis conducted with actual emergency workers.

\section{Works Cited}

[1]. An T. Oskarsson, C. R. (2010). The AlphaACT Decision Support System for Emergency Responders. Ergonomics Society Annual Meeting Proceedings of the Human Factors and Ergonomics Society Annual Meeting, (pp. 417-422).

[2]. Anonymous. (2011, 02 07). Smart911 Improves Safety for Nearly 4 Million Citizens throughout United States. Retrieved from Smart911 Improves Safety for Nearly 4 Million Citizens throughout United States: http://web.ebscohost.com.libproxy.adelphi.edu:2048/ehost/detail?sid=b7b05ca5-2c6d-45fb-b196-

713b88296ca6\%40sessionmgr115\&vid=3\&hid=119\&bdata=JnNpdGU9ZWhvc3QtbG12ZSZzY29wZT1zaXRl\#db=bwh\&AN=bizwir e.c31897335

[3]. Anonymous. (2013, 01 07). Health Data Management15. 6 (Jun 2007): 8. . Retrieved from Health Data Management15. 6 (Jun 2007): 8. : http://search.proquest.com.libproxy.adelphi.edu:2048/docview/219566129/13B7B357C1022F10160/1?accountid=8204

[4]. Chris, P. (2013, 01 07). First responders need improved technology to help convey information in times of crisis . Retrieved from First responders need improved technology to help convey information in times of crisis : http://web.ebscohost.com.libproxy.adelphi.edu:2048/ehost/detail?sid=68af4d60-9760-44a6-be17-

7b08b00475ae\%40sessionmgr111\&vid=1\&hid=119\&bdata=JnNpdGU9ZWhvc3QtbG12ZSZzY29wZT1zaXR1\#db=bwh\&AN=L549 $9187 \mathrm{NOCB}$

[5]. Dawes, S. S., Cresswell, A. M., \& Cahan, B. B. (Apr 2004). Learning From Crisis. Lessons in Human and Information Infrastructure From the World Trade Center Response. Social Science Computer Review, 52-66.

[6]. Dionysios Kostoulas, R. A. (2008). A nature-inspired decentralized trust model to reduce information unreliability in complex disaster relief operations. . Advanced Engineering Informatics, 45-58.

[7]. Jere, M. (2013, 01 07). Patents; Patent Application Titled "System and Method for Managing Mobile Hie Information" Under Review. Retrieved from Patents; Patent Application Titled "System and Method for Managing Mobile Hie Information" Under Review: http://search.proquest.com.libproxy.adelphi.edu:2048/docview/1222396471/abstract? source=fedsrch\&accountid=8204

[8]. Kovalcik, M. (2010). Preplanning Software. Fire Engineering, 111.

[9]. L A Lenert, D. K. (2011). Design and evaluation of a wireless electronic health records system for field care in mass casualty settings. J Am Med Inform Assoc, 842-852.

[10]. Marsden, J. ,. (2012). Dynamic emergency response communication: The Intelligent Deployable Augmented Wireless Gateway (iDAWG). 2012 IEEE International Multi-Disciplinary Conference on Cognitive Methods in Situation Awareness and Decision Support, CogSIMA 2012 (pp. 279-286). New Orleans, LA: Cognitive Methods in Situation Awareness and Decision Support (CogSIMA), 2012 IEEE International Multi-Disciplinary Conference.

[11]. Messner, R., Hludik, F., Vidacic, D., \& Melnyk, P. (2005). An integrated command control and communications center for first responders. Proceedings of the SPIE - The International Society for Optical Engineering (pp. 57-70). Orlando, FL USA: SPIE - The International Society for Optical Engineering. 
Appendix “A” - EMT First Responders Information Technology

EMT First Responders Information Technology

Incident Collection Form

\begin{tabular}{|l|l|}
\hline Log\#; & \\
\hline Date; & \\
\hline Responders Job Title; & \\
\hline Sex (M,F); & \\
\hline Age; & \\
\hline
\end{tabular}

Description of Information Technology that proved beneficial during response;

Description of Information Technology that was not available but would have been beneficial during response; 